\title{
EFEITO TERAPÊUTICO DA FIBRA GOMA-GUAR PARCIALMENTE HIDROLISADA NA CONSTIPAÇÃO INTESTINAL FUNCIONAL EM PACIENTES HOSPITALIZADOS
}

\author{
Geise Maria da Silva BELO ${ }^{1}$, Alcides da Silva DINIZ² e Ana Paula Campos PEREIRA ${ }^{1}$
}

\begin{abstract}
RESUMO - Avaliação do impacto da fibra goma-guar parcialmente hidrolisada na constipação intestinal funcional em pacientes hospitalizados. Ensaio clínico com 64 adultos, randomizados para duas dietas: grupo 1 dieta laxante ( $\pm 30 \mathrm{~g}$ de fibras) e grupo 2 mesma dieta $+10 \mathrm{~g}$ de fibra goma-guar parcialmente hidrolisada, durante 15 dias. A dieta laxante ou acrescida da referida fibra reduziu em $78 \%$ a constipação intestinal funcional, assim como sua adição não provocou efeito adicional na freqüência evacuatória, consistência fecal, uso de laxativos, embora tenha reduzido a sintomatologia gastrointestinal. Fibras devem ser utilizadas no tratamento da constipação intestinal funcional; entretanto, a suplementação com fibra goma-guar parcialmente hidrolisada precisa ser melhor investigada.
\end{abstract}

DESCRITORES - Constipação intestinal. Fibra alimentar. Gomas vegetais. Pacientes internados.

\section{INTRODUÇÃO}

A constipação intestinal funcional (CIF) é uma síndrome decorrente de distúrbios da motilidade enterocolônica e apresenta elevada prevalência na população mundial ${ }^{(5)}$. O papel da alimentação, como causa ou agravante da CIF, requer atenção especial para melhor compreensão dessa entidade nosológica. A industrialização de alimentos visando sua conservação, ocasionou a obtenção de produtos de maior valor calórico e nutricional porém, como conseqüência, houve maior refinamento dos alimentos, com conseqüente redução da oferta e ingestão de fibras. Este fato resultou na diminuição dos estímulos propulsivos, ocasionando incapacidade progressiva do intestino grosso para deslocar os resíduos fecais para sua expulsão ${ }^{(2,5)}$.

O consumo de fibras alimentares é reconhecido como uma das bases para um estilo de vida saudável, oferecendo proteção contra várias doenças e agravos $^{(1)}$. Recentemente, a indústria alimentícia vem desenvolvendo uma variedade de carboidratos de baixo peso molecular que se comportam no organismo como fibras, a exemplo da goma-guar parcialmente hidrolisada (GGPH), embora seu efeito terapêutico na CIF continue sendo avaliado ${ }^{(3,4)}$.

Este estudo objetivou testar o impacto da suplementação dietética com fibras GGPH no tratamento da CIF em pacientes hospitalizados.

\section{MÉTODOS}

\section{População de estudo}

Pacientes internados no setor de traumatologia do Hospital da Restauração, em Recife, PE, entre 18 a 64 anos, de ambos os sexos que, a partir do $7^{\circ}$ dia em regime de dieta normal, apresentaram CIF. Foram considerados os seguintes critérios de exclusão: gravidez, doença psiquiátrica, neurológica ou metabólica sistêmica, doença orgânica do cólon, úlcera péptica, fibroma uterino, diástase de musculatura e hérnias abdominais, e cirurgia gastrointestinal prévia.

\section{Desenho do estudo}

Ensaio clínico, de base hospitalar, randomizado, cego, em que os pacientes com diagnóstico de CIF foram alocados em dois grupos de tratamento: um grupo recebeu a dieta laxante do hospital (DLI), com teor médio de fibras de $28,96 \pm 5,86 \mathrm{~g} / \mathrm{dia} ;$ o outro dieta laxante institucional + goma-guar (DLIGG), ingeriu a mesma quantidade de fibras, acrescida de $10 \mathrm{~g}$ de fibra GGPH.

\section{Amostragem}

Baseado nas estimativas de redução na CIF nos dois grupos de tratamento, a partir do estudo piloto e adotando os níveis de significância de $5 \%$, para o erro alfa $(\alpha)$ e $10 \%$ para o erro beta $(\beta)$, o tamanho da amostra foi

Ensaio clínico realizado no Hospital da Restauração da cidade do Recife, mantido pela Secretaria Estadual de Saúde de Pernambuco, Recife, PE.

${ }^{1}$ Hospital da Restauração da Secretaria Estadual de Saúde de Pernambuco; '2Departamento de Nutrição da Universidade Federal de Pernambuco, Recife, PE.

Correspondência: Dra. Geise Maria da Silva Belo - Av. José Augusto Moreira, 1791 - apt. 304 - Casa Caiada - 53130-410 - Olinda, PE. E-mail: geisebelo@bol.com.br 
calculado, pela fórmula $n=\left(p_{1} q_{1}+p_{2} q_{2}\right) \cdot(z \alpha+z \beta)^{2} /\left(p_{1}-p_{2}\right)^{2}$ onde, $\mathrm{p}_{1}$, prevalência de CIF com uso de DLI (50\%) e $\mathrm{p}_{2}$, prevalência de CIF com uso de DLIGG (14\%). Foi obtido o número de 31 pacientes para constituir cada grupo de estudo. Em virtude das perdas, corrigiu-se a amostra em $30 \%$, totalizando 40 pacientes no grupo DLI e 41 no grupo DLIGG.

\section{Variáveis-resposta}

O impacto do tratamento foi avaliado pela freqüência evacuatória, consistência fecal dura, tempo de resposta da função intestinal, necessidade de uso de laxativos e sintomatologia gastrointestinal.

\section{Características da dieta e suplemento}

O teor de fibras na dieta laxante foi calculado pela pesagem direta dos alimentos, antes e após as refeições; a fibra GGPH (Novartis Consumer Health, Suíça) foi pesada em balança digital e separada em porções individuais de $10 \mathrm{~g}$, oferecida diariamente, adicionada ao suco de frutas, às $9 \mathrm{~h}$ da manhã pelo copeiro, sob supervisão do nutricionista.

\section{Análise dos dados}

As variáveis contínuas, com distribuição normal e homocedasticidade, tiveram suas médias inter e intragrupos comparadas pelos testes $t$ de Student, para dados não-pareados e pareados, respectivamente. As proporções foram comparadas pelo teste do qui ao quadrado de Pearson. Foi adotado o nível de significância de 5\% para o teste de normalidade das variáveis, bem como para a rejeição da hipótese de nulidade.

\section{Considerações éticas}

O protocolo do estudo foi aprovado pelo Comitê de Ética em Pesquisa do Hospital da Restauração, conforme resolução 196/96 do Conselho Nacional de Saúde sobre pesquisas envolvendo seres humanos.

\section{RESULTADOS}

Foram estudados 81 pacientes. As perdas $(n=17)$ ocorreram em virtude da solicitação de 1 paciente para sair do estudo, e 16 não completaram o tempo previsto devido à alta hospitalar ou transferência para outra instituição.

\section{Comparabilidade entre os grupos de estudo}

As características biossociais, clínicas e terapêuticas no momento da intervenção, foram semelhantes entre os dois grupos de estudo, exceto para a ocorrência de fezes duras que predominou no grupo DLIGG. As perdas apresentaram as mesmas características nos dois grupos de tratamento.

\section{Efeitos da intervenção}

$\mathrm{Na}$ análise do impacto intragrupo houve aumento na média semanal de evacuações, após 7 dias da intervenção, tanto no grupo DLI $(P=0,001)$, quanto no grupo DLIGG $(P=0,000)$, com estabilização dessas médias no $15^{\circ}$ dia pós-intervenção. No entanto, na comparação intergrupos, verificou-se que o incremento foi similar entre os dois grupos de tratamento, tanto no $7^{\circ}$ dia $(P=0,315)$, quanto no $15^{\circ}$ dia $(P=0,243)$. No entanto, o tempo médio de dias para resposta da função intestinal foi similar entre os dois grupos $(P=0,274)$, bem como a necessidade de uso de laxativos $(P=0,071)$. O grupo DLI relatou ocorrência maior $(P=$ $0,012)$ de queixas abdominais, principalmente flatulência, quando comparado ao grupo que recebeu a DLIGG. Por sua vez, houve redução de fezes de consistência dura, tanto no grupo DLI quanto no grupo DLIGG, porém sem diferença estatística significante entre eles $(P=0,252)$ (Tabela 1$)$.

A resposta global ao tratamento com fibras mostrou que $50 \mathrm{de}$ 64 pacientes normalizaram a função intestinal no final do estudo. Entretanto, não houve potencialização no efeito terapêutico naqueles pacientes que receberam DLIGG $(P=0,281)$.

TABELA 1. Impacto da dieta laxante e da fibra goma-guar parcialmente hidrolisada na consistência fecal dura, na necessidade do uso de laxativos, sintomatologia gastrointestinal, tempo de resposta da função intestinal e média de evacuações em pacientes hospitalizados

\begin{tabular}{|c|c|c|c|c|c|}
\hline \multirow{2}{*}{ Efeitos das intervenções } & \multicolumn{2}{|c|}{$\begin{array}{l}\text { Grupo } \mathrm{DLI}^{1} \\
\quad(\mathrm{n}=33)\end{array}$} & \multicolumn{2}{|c|}{$\begin{array}{l}\text { Grupo DLIGG }{ }^{2} \\
\quad(\mathrm{n}=31)\end{array}$} & \multirow{2}{*}{$P$} \\
\hline & $\mathrm{n}$ & $\%$ & $\mathrm{n}$ & $\%$ & \\
\hline Consistência fecal dura & 13 & 39,4 & 8 & 25,8 & $0,252 * *$ \\
\hline Necessidade do uso de laxativos & 9 & 27,3 & 3 & 9,7 & $0,071 * *$ \\
\hline Sinais e sintomas gastrointestinais & 25 & 76,0 & 13 & 42,0 & $0,012 * *$ \\
\hline $\begin{array}{l}\text { Tempo de resposta da função } \\
\text { Intestinal (dias) }\end{array}$ & 33 & $2,7 \pm 2,4^{*}$ & 31 & $2,1 \pm 1,9 *$ & $0,274 * * *$ \\
\hline Média de evacuações (semanal) & 33 & $3,9 \pm 2,6^{*}$ & 31 & $4,6 \pm 2,4^{*}$ & $0,243 * * *$ \\
\hline
\end{tabular}

O incremento significativo na média de evacuações semanais, observado já no $7^{\circ}$ dia de intervenção, assim como a manutenção desse efeito ao curso dos 15 dias de tratamento, vem ratificar o papel terapêutico da fibra na CIF. Esse impacto significativo tem sido relatado em estudos que fizeram uso de fontes diversificadas de fibras. No entanto, o aporte adicional de fibra GGPH não produziu nenhum efeito adicional, em termos de incremento na média de evacuações, quando comparado ao tratamento com menor teor de fibras. Vale salientar que o grupo de pacientes que recebeu a suplementação de fibra GGPH apresentou, por ocasião da randomização, proporção significantemente maior de indivíduos com relato de fezes com consistência dura, em relação aos pacientes que receberam apenas a dieta laxante. Esse fato poderia, a princípio, mascarar o potencial efeito da fibra GGPH. No entanto, resultados similares, descritos por STASSE-WOLTHUIS et al. ${ }^{(2)}$, mostraram que o acréscimo de $12 \mathrm{~g}$ de farelo de trigo a uma dieta rica em vegetais e frutas, não apresentou nenhum efeito na média de evacuações semanais. Deve-se destacar que, nesse estudo, a quantidade de fibras presente no grupo que recebeu apenas a dieta com vegetais e frutas tem sido considerada abaixo dos teores usualmente recomendados na conduta dietoterápica frente à CIF. Nesse sentido, BADIALI et al. ${ }^{(1)}$ demonstraram que uma dieta contendo cerca de $15 \mathrm{~g} / \mathrm{dia}$ de fibra foi tão efetiva na função colônica quanto uma dieta similar acrescida de farelo de trigo. 
$\mathrm{Na}$ presente série, a rápida resposta da função intestinal, tanto com a dieta laxante exclusiva quanto com a dieta laxante acrescida de fibra GGPH, vem demonstrar que a fibra teria, em princípio, ação reguladora do trânsito intestinal, contribuindo para a reversão do quadro de CIF em pacientes hospitalizados. No entanto, o tempo de resposta similar entre os dois tratamentos, mostrou que não houve potencialização do efeito regulador com uso da fibra GGPH.

A maior ocorrência de queixas gastrointestinais no grupo que utilizou apenas a dieta laxante foi um resultado inesperado, uma vez que a literatura especializada ${ }^{(1,3)}$ tem relatado que o aparecimento e a intensidade de sinais e sintomas abdominais aumentam proporcionalmente com o incremento na quantidade de fibras consumidas. No caso específico da flatulência, em que os pacientes que receberam a dieta com fibra GGPH referiram menos queixas, quando comparado àqueles que receberam apenas a dieta laxante, constitui-se também em achado não previsível. Nesse sentido, TAKAHASHI et al. ${ }^{(3)}$ observaram aumento significativo da flatulência quando utilizaram fibra GGPH em mulheres constipadas. Do ponto de vista fisiológico, este seria um achado clínico mais compatível, uma vez que a fibra GGPH é solúvel, altamente fermentável e que pode ter, como possível efeito adverso, o aumento da flatulência no início do tratamento, resultado da fermentação bacteriana. Entretanto, BADIALI et al. ${ }^{(1)}$ observaram que a ocorrência e a intensidade de flatulência foram similares entre pacientes que utilizaram tanto a dieta rica em fibras quanto a mesma dieta acrescida de farelo de trigo.

A similaridade entre os grupos quanto à necessidade do uso de laxativos, mostra que o uso de maior quantidade de fibra na dieta não potencializaria o seu efeito terapêutico frente à CIF. A melhora significativa da consistência fecal, com redução da ocorrência de fezes duras, observada durante o tratamento tanto com a dieta laxante institucional quanto na dieta laxante acrescida de fibra GGPH, poderia ser atribuída à ação das fibras, que levariam a maior retenção de água nas fezes, como também ao aumento da própria massa bacteriana proveniente da fermentação das fibras. No caso específico da fibra GGPH, TAKAHASHI et al. ${ }^{(4)}$, observaram aumento significativo da umidade fecal e que a correlação inversa entre o $\mathrm{pH}$ e a umidade fecal resultou em fezes macias, com aumento significativo da freqüência evacuatória em pacientes constipados.

\section{CONCLUSÃO}

A intervenção dietoterápica com fibras alimentares causou impacto significativo na remissão do quadro de CIF em pacientes hospitalizados, com aumento considerável na média de evacuações semanais, embora com percentual elevado de sintomatologia gastrointestinal. Entretanto, o uso adicional de fibra GGPH não resultou em maior impacto na função evacuatória.

Este impacto da dieta rica em fibras no tratamento da CIF nos pacientes hospitalizados, vem demonstrar a eficácia desta conduta dietoterápica, particularmente em pacientes acamados. Logo, uma dieta rica em fibras deveria ser recomendada, como ação de primeira linha, no tratamento da CIF. Entretanto, o papel terapêutico da fibra GGPH precisa ser melhor investigado para a sua inclusão no manejo dietoterápico de pacientes com este distúrbio gastrointestinal.

Belo GMS, Diniz AS, Pereira APC. Effect of partially hidrolized guar-gum in the treatment of functional constipation among hospitalized patients. Arq Gastroenterol. 2008;45(1):93-6.

ABSTRACT - The effect of hydrolyzed partially guar-gum was evaluated in the treatment of functional constipation among hospitalized patients. Following a

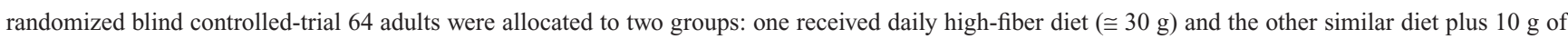
hydrolyzed partially guar-gum, during 15 days. Dietary fiber reduced functional constipation by $78.0 \%$. Hydrolyzed partially guar-gum did not show any additional effect in defecation frequency, fecal consistence, need of laxative drug use, although a reduction in bowel complaints. Dietary fiber may be used in the treatment of functional constipation. However the therapeutic role of hydrolyzed partially guar-gum should be further investigated.

HEADINGS - Constipation. Dietary fiber. Plant gums. Inpatients.

\section{REFERÊNCIAS}

1. Badiali D, Corazziari E, Habib FI, Tomei E, Bausano B, Magrini P, Anzini F, Torsoli A Effect of wheat bran in treatment of chronic nonorganic constipation. A double-blind controlled trial. Dig Dis Sci. 1995;40:349-56.

2. Stasse-Wolthuis M, Albers HF, Van Jeveren JG, Wil de Jong J, Hauvast JG, Hermus RJ, Katan MB, Brydon WG, Eastwood MA. Influence of dietary fiber from vegetables and fruits, bran or citrus pectin on serum lipids, fecal lipids, and colonic function. Am J Clin Nutr. 1980;33:1745-56.

3. Takahashi H, Yang SI, Hayashi C, Kim M, Yamanaka J, Yamamoto TE. Effect of partially hydrolyzed guar gum on fecal output in human volunteers. Nutr Res. 1993;13:649-57.
4. Takahashi H, Wako N, Okubo T, Ishihara N, Yamanaka J, Yamamoto T. Influence of partially hydrolyzed guar gum on constipation in women. J Nutr Sci Vitaminol (Tokyo). 1994;40:251-9

5. Talley NJ. Management of chronic constipation. Rev Gastroenterol Disord. 2004;4:18-24. 